\title{
A Life Dedicated to the Science, Philosophy and Romanian Society
}

\author{
G. Tecuci
}

Gheorghe Tecuci

Romanian Academy

George Mason University

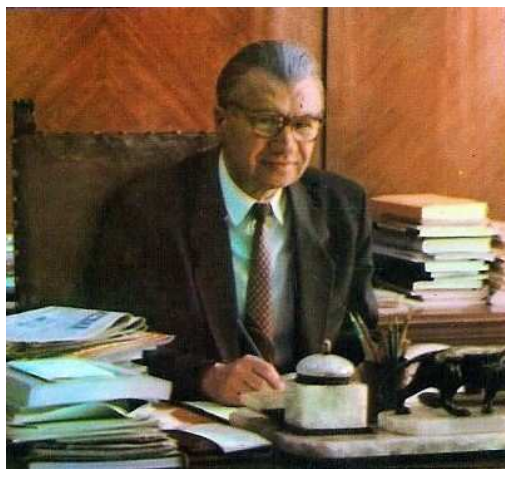

Mihai Drăgănescu

With outstanding contributions in Electronics, Informatics, and Philosophy, and as Professor, Researcher, and Manager, Acad. Mihai Drăgănescu is the most important encyclopedic personality of contemporary Romania.

Educated in the nascent Romanian school of electronics, Acad. Mihai Drăgănescu creates a worldclass school of electronic devices and microelectronics. Envisioning the evolution of the modern society, becomes initiator and promoter of the informatics revolution in Romania, conceptually defining it and coordinating its development. Generalizing the concept of information, creates an original philosophy that leads to the development of a new type of science, called structural-phenomenological, with major implications for the understanding of the world and its future. First president of the Romanian Academy renaissance, he leads both its return to its role and traditional sources, and its renewal and adaptation to the evolution of the civilization. Promoter of the scientific and humanistic culture, brings back the deserved recognition to major personalities of the Romanian spirituality. Mentor and life model, he lightens and encourages many young generations with an extraordinary generosity.

Any of these achievements would be enough to place Acad. Mihai Drăgănescu among the greatest Romanian personalities. Their combination, impressive through their diversity and unity, creates the image of a personality of a rare complexity and creativity.

\section{Founding Father of the Romanian School of Electronic Devises and Mi- croelectronics}

Acad. Mihai Drăgănescu was educated as an electronics engineer, and climbed through all the professional levels, from assistant professor to academician. Despite the unsupportive research environment of an isolated Romania, he succeeded in obtaining truly outstanding results. At the beginning of his scientific career, as a young assistant professor, Mihai Drăgănescu is among the very few Romanian electronics engineers with world-class research results, author of the first Romanian $\mathrm{PhD}$ in the area of 
electronic devises, entitled "The Capacities of Electronic Tubes and Their Dependence of the Functioning Conditions". This is followed by other fundamental research results, such as the Matz-Drăgănescu theory of the transistor at high-level of injection, the study of the inductive effects in semiconductor devices, and the simplification of the dielectric diode theory. They represent the prelude of "Electronic Processes in Semiconductor Devices of Circuits" [1], one of the first authored books in this domain in the world and an exceptional achievement in the Romania of 1962, recognized with the State Prize. In 1963 he publishes the first Romanian study on Microelectronics [2], and is awarded the Prize of the Ministry of National Education for his scientific research. He establishes and heads the Research Institute for Electronic Components, in 1969, and teaches the first course on Integrated Circuits, in 1970. In 1972 he publishes "Solid State Electronics" [3], the second fundamental book of the Romanian School of Electronic Devices.

A unifying understanding of Electronics, Informatics and Philosophy, in a social context, leads Prof. Drăgănescu to the development of a basic discipline of the science and technology of information, which he calls "Functional Electronics". In 1978 he starts teaching this new discipline at the 'Politehnica' University of Bucharest. Then, in 1991, he publishes the book "Functional Electronics" [4], followed by several studies, including "Microelectronics and Functional Electronics" [5], "From solid state to quantum and molecular electronics, the deepening of information processing" [6], and "Neural Engineering and Neural Electronics Facing Artificial Consciousness" [7].

In an activity spanning almost 50 years, through original research, the publication of world-class foundational books, the development of new courses, the formation and support of a large number of specialists, the guidance of the Romanian industry of electronics and computers, including the management of the manufacturing of the integrated circuits, Acad. Mihai Drăgănescu has created the Romanian School of Electronic Devices and Microelectronics, significantly influencing the evolution of the Romanian society.

As an international recognition of his exceptional contributions, Acad. Mihai Drăgănescu is elected Fellow IEEE in 1994, Life Fellow IEEE in 1997, and receives the Millennium III Medal from IEEE in 2000 .

\section{Initiator and Promoter of the Information Revolution in Romania}

Acad. Mihai Drăgănescu is credited with envisioning the information revolution, with its conceptual definition, and with the coordination of its development in Romania [8]. Initiator and leader of the first and only national major technologic program in the area of integrated circuits, computers and informatics, Acad. Mihai Drăgănescu has guided for 20 years, between 1965 and 1985, the economic evolution of Romania in these areas, making numerous critical decisions, including the transitioning of Romania to the silicon phase in the electronics domain, and the buying of western licenses for the manufacturing of integrated circuits and of 3rd generation computers. In 1971 he is awarded the French order "Commandeur de la Legion d'Honneur" for his contributions to the Romanian-French collaboration in Informatics.

His studies, dating back to 1970, envisioned a future information society (now a reality in the advanced countries), based on an informatics medium aimed at serving each individual, organization, and society as a whole, both in realizing its own functions and in their relationships with each other. Moreover, Acad. Mihai Drăgănescu had the vision (now confirmed by the evolution of the Internet) that such a medium had to be based on an evolving informatics system, adaptable to the evolution of computers and society. It could not be planned in the smallest details, as required by the political leaders of Romania of that time [8].

Integrating theoretical research, a global systemic vision, and a creative management, Acad. Mihai Drăgănescu has laid the basis for the development of Informatics in Romania through several outstanding initiatives. They include the establishment of important institutions, such as the Company for the 
Maintenance and Repair of Computing Tools (IIRUC, 1968), the Institute of Computers (ITC, 1969), and the Institute of Electronic Components (ICE, 1969). An important moment was the establishment, in 1971, of the Central Institute for Informatics which, under his leadership, has quickly become the center of the Romanian informatics, both through world-class research in advanced domains (e.g., artificial intelligence, industrial informatics, computer networks) and through the coordination of the development of informatics in the entire country (e.g., the coordination of a network of 40 territorial computer centers, established between 1968 and 1985). At the same time computer centers have been established in universities and research institutes, as well as computer science high schools, and new university degree programs in electronics, automation, computers and informatics.

In late 70, Acad. Mihai Drăgănescu proposes a new major national program for the transitioning of Romania into the second industrial revolution, based on electronics, automation and informatics $[9,10]$. Not only that the political leadership of Romania rejects this visionary proposal, but the development of informatics is purposely slowed down and, in 1985, even the Central Institute for Informatics is dismantled. "In 1985, a terrible blow was given to the information society in formation" [11]. However, even during this tragic period in his own life and that of the country, Acad. Mihai Drăgănescu formulates the idea of a future knowledge society, idea widely accepted today [12].

In the aftermath of the Romanian Revolution of 1989, Acad. Mihai Drăgănescu resumes his role of promoter of the information revolution. He establishes the National Commission for Informatics (1990), the Center for New Electronics Architectures (1991), the Section for Science and Technology of Information of the Romanian Academy (1992), the Research Institute for Artificial Intelligence (1994) and the Forum for the Information Society (1997).

Later on, Acad. Mihai Drăgănescu formulates a new vision for the evolution of the society, defining the era of information, with three stages, the Information Society, the Knowledge Society, and the Consciousness Society [12]. "In essence, the Information Society is the society based on Internet" Romania being in a state of underdevelopment of this society [12]. "For Romania the development of the Information Society is essential, but in the current situation this has to take place at the same time with achieving the first objectives of the Knowledge Society. It is wrong to say: First the Information Society and then the Knowledge Society. We should not sentence ourselves to be perpetually delayed" [12].

Acad. Mihai Drăgănescu identifies technological and functional vectors as tools that can transition the Information Society to the Knowledge Society: "To take first steps into the Knowledge Society it is necessary to employ a minimum number of such vectors. The first vector is the development of an 'advanced' Internet, which is a technological vector, then the technology of electronic books (technological vector) and the knowledge management (functional vector with two valences, one for the economic and organizational functioning of a company, multinational corporation or society, and the other one for the moral utilization of knowledge in the global society)" [12].

Similar to the national program from 1965-1985, the Program for the Information and Knowledge Society [12] is a very significant contribution of Acad. Mihai Drăgănescu, with precise objectives and means, of greatest importance for the progress of the Romanian society in the global economy.

\section{Creator of the Structural-Phenomenological Philosophy of Existence (Orthophysics)}

A profound understanding of physics, electronics, informatics and biology, a great analytic, synthetic and unifying spirit, an irresistible philosophical tension, in the context of the Romanian spirituality, have led Acad. Mihai Drăgănescu to the creation of an original philosophy of existence, fascinating through its naturalness and generality, a philosophy which, according to the illustrious philosopher Constantin Noica, "will deeply amaze and impress the unsuspecting thinkers of the XXI century" [13].

Acad. Mihai Drăgănescu realizes that "the ontological model which is at the basis of the structural 
science is inadequate, and the structural science itself is limited, it can only be used between certain limits of reality. Beyond these limits it is insufficient to explain the reality because it neglects extra ingredients of nature which in cannot recognize due to the character of the methods used. Overall, the structural science is incomplete and cannot explain the reality in its entirety" [14].

Through fundamental works, such as The Depths of the Material World [15], Orthophysics [16], Spirituality, Information, Matter [17], Essays [19], L'Universalité ontologique de l'information [20], Acad. Mihai Drăgănescu has developed an original ontological model which, for the first time, explains in a unified way the physical, biological, informational, mental, and psychological processes, based on original fundamental concepts such as informatter, orthoenergy, orthoexistence, orthosense, phenomenological sense, intro-openness, and others. Acad. Mihai Drăgănescu postulates the existence of a tendencial deep reality, with an energetic component (orthoenergy) and an informational one (informatter), outside space and time, from which physical universes are generated, where the non-living matter is a coupling between orthomatter with orthoenergy and informatter, while living organisms contain directly informatter, thus forming rings of existence.

The Orthophysics philosophy proposes to overcome the paradoxes of the current structural science by developing a new type of science, called structural-phenomenological, for which Acad. Mihai Drăgănescu has formulated several principles, such as the principle of insufficiency of structural knowledge, the principle of existence, of profound matter, of the ontological universality of the information and energy, of the tendencies of becoming, and of the structural-phenomenological modeling [21].

As philosopher Constantin Noica before him, Acad. Mihai Drăgănescu has made philosophy relying first and foremost on "the pure thought uninfluenced, let flowing in his mind ... feeling than the need of confrontation with the established philosophy and science, but giving science a more prominent role" [19, p.104].

Other great thinkers, such as Florian Nicolau, David Bohm and John Archibald Wheeler, have themselves imagined a more profound stratum of reality than that offered by the structural science, but none has advanced so much in this direction as Acad. Mihai Drăgănescu, who has thus made a major contribution to the human thought. Today, an increasing number of scientists in physics, chemistry, and information science adopt points of view that are close to those initially proposed by Acad. Mihai Drăgănescu, confirming the importance and the ramifications of his contributions.

A convincing argument for the generality of the orthophysics philosophy of existence is the explanation of the notion of God. The question on the relationship between the orthophysics philosophy and God was raised by Constantin Noica, in 1987. The answer is given by Acad. Mihai Drăgănescu years later, in 2003, following his interactions with Prof. Menas Kafatos, illustrious American astrophysicist and philosopher who postulated the existence of the consciousness of the universe [22].

Following a long investigation in the orthophysics philosophy, and using only the already defined principles, Acad. Mihai Drăgănescu devices a phenomenological-structural model of existence. "Which is the relationship between the phenomenological-structural model of the fundamental consciousness of existence and the notion of God from the great and important religions of the world? There is no doubt a very strong relationship, the notion of God in these religions potentially being a certain way of perceiving the fundamental consciousness of existence. If we accept the existence of the fundamental consciousness as being very plausible, then God is also very plausible from the scientific and philosophical point of view, even though $\mathrm{He}$ is perceived with different nuances. ... the same way the cosmos is not an organism, the fundamental consciousness does not belong to an organism, yet it exists. The fundamental consciousness of existence is the being by excellence, beyond life and, implicitly, beyond death." [23]

The fruitful collaboration with Prof. Menas Kafatos, with whom Acad. Mihai Drăgănescu has many points of view in common, has led to the development of a new integrated approach to science, which takes into account both the structural and the phenomenological aspects of reality [24, 25].

The publication of a large number of papers, the organization of several conferences on the "structuralphenomenological modeling" at the Romanian Academy, the emerging of disciples, the collaboration 
with reputable scientists, the adoption of similar concepts by an increasing number of thinkers, all these confirm Noica's characterization of the orthophysics philosophy [13].

\section{Initiator and Manager of the Romanian Academy Renaissance}

Next year the Romanian Academy will celebrate 20 years from its renaissance following the Romanian revolution of 1989. In a short period of only four years, between 1990 and 1994, as President of the re-born Romanian Academy, Acad. Mihai Drăgănescu has initiated and led the return of this primary forum of the Romanian spirituality to its traditional role and sources, as well as its renewal and adaptation to the future tendencies of the scientific and humanistic culture, in the national, European and world context.

We only need to reflect on the evolution of the Romanian society during the never-ending period of transition to understand that Acad. Mihai Drăgănescu was the right person, at the right place and at the right time. As Vice Prime Minister in the first provisional government, Acad. Mihai Drăgănescu sets the renaissance of the Romanian Academy (which was condemned at physical death by the Ceasusescu's regime) as top priority for the new government which, on January 5th, 1990, promulgates the DecreeLaw no. 4 on the organization and functioning of the Romanian Academy, reestablishing its autonomy.

One of the first measures the re-born Romanian Academy under the leadership of Acad. Mihai Drăgănescu was to right the wrongs of history. Are recognized as members without interruption of the Romanian Academy the illustrious representatives of the Romanian spirituality, abusively eliminated in 1948 by the Communist regime, such as Lucian Blaga, Theodor Capidan, Dumitru Caracostea, Ion Petrovici, Constantin Rădulescu-Motru, Gheorghe I. Brătianu, Silviu Dragomir, Dimitrie Gusti, Alexandru Lepădatu, Ioan Lupaş, Simion Mehedinţi, Petre P. Negulescu, Nicolae Colan, Victor Slăvescu, Constantin Brăiloiu, Tiberiu Brediceanu, Onisifor Ghibu, Pantelimon Halipa, Dragomir Hurmuzescu, Grigore T. Popa, Petru Sergescu, Emil Haţieganu, Iuliu Hossu, Constantin Levaditi, Iuliu Maniu, Nicolae Bălan, Grigore Tăuşan, and others [19, p.153].

Shining stars who have not received their well-deserved recognition during their lives, are elected posthumously as members of the Romanian Academy: Constantin Brâncuşi, Mircea Eliade, Constantin Noica, Ştefan Lupaşcu, Mircea Florian, Nichita Stănescu, Marin Preda, Ion Barbu, Traian Lalescu, Constantin Pârvulescu, Călin Popovici, Ion Moraru, Ştefan Berceanu, Virgil Madgearu, Petre Andrei, Petru Caraman, Nicolae C. Paulescu, Alexandru Proca, Haralambie Vasiliu, Ştefan Odobleja, Bela Bartok, Herman Oberth, Eugen Lovinescu and Theodor Aman [19, p.153].

The Romanian Academy regains its historic role as forum of all Romanians through the election of honorary members from Bessarabia (Grigore Vieru, Ion Druţă, Mihai Cimpoi, Andrei Andries, Sergiu Ion Rădăuţan), Bucovina (Grigore Constantin Bostan şi Alexandrina Cernov), and the Romanian diaspora (Nicolae Georgescu-Roegen, Anghel Rugină, Radu Bălescu, Sergiu Celibidache, Alexandru Cioranescu, Joseph M. Juran, George Uscăţescu, Ion I. Inculeţ, Dinu Adameşteanu, Mihai Ion Botez, Eugenio Coşeriu, Nicola Matteesco-Matte, Jean Negulesco, Dinu C. Giurescu, Iosif Antochi, Paul Stahl, Petru Dumitriu, Mattei Dogan, Idel Ianchelevici, Constantin Atanasie Bona, and other [19, p.154], [26, p. 154-155].

Acad. Mihai Drăgănescu founds, writes its manifesto, and leads "Academica", the Romanian Academy journal destined to maintain a continuous connection with the Romanian intellectuality. Well-thinking the role of the Romanian nation in the development of the universal scientific and humanistic culture, Acad. Mihai Drăgănescu succeeds in bringing over 50 institutions of fundamental and advanced research back into the Romanian Academy, and in resurrecting institutions of tradition, successfully defending their activity against powerful opposition from various national and international forums. At the same time, Acad. Mihai Drăgănescu leads the adaptation of the Romanian Academy to the global tendencies through the founding of the Section of Arts, Architecture and Audio-Visual, the Section of Science and Technology of Information, as well as several new institutes and centers. 
Another impact on the Romanian Academy by the first president of its renaissance is his initiation of the election of about 50 of its members.

\section{Promoter of the Romanian Scientific and Humanistic Culture}

We have already mentioned the major role played by Acad. Mihai Drăgănescu in the development of Electronics, Informatics and Philosophy. But his role as promoter of the Romanian scientific and humanistic culture is much wider than his extraordinary achievements in these areas. Consider, first of all, his determining role in the reestablishment of the natural orthography of the Romanian language, abusively altered in 1953, through political diktat contrary to the national culture. This act, of primary importance for the Romanian language, as well as the others already mentioned, shows the extraordinary humanistic and patriotic qualities of Acad. Mihai Drăgănescu. The request by the illustrious linguist, Acad. Alexandru Rosetti, of reestablishing â in the Romanian orthography, expressed just before his passing into eternity, was a "testamentary request" for Acad. Mihai Drăgănescu [26, p.206]. As a consequence, on January 31st 1991, he delivers the speech "On Several Rectifications of the Romanian Language Orthography" at the Romanian Academy [19, p.162-170]. Following a wide public debate, where he confronted the vicious opposition of several linguists and part of the press with numerous scientific arguments, Acad. Mihai Drăgănescu delivers, on February 17th, 1993, the historical speech "The Romanian Language Orthography: With Hasdeu, Maiorescu, Puşcariu and Rosetti", urging "Let us have the consciousness of our past, aspirations, and destiny. Let us defend our culture, language, and soul." [19, p.171-194]. The almost unanimous vote (with only one against) of the members of the Romanian Academy, as well as the support of the Saint Synod of the Romanian Orthodox Church, the Ministry of Education, and the Ministry of Culture, have changed the accusation of imposing "the Drăgănescu's orthography" into a title of glory [26, p. 158].

The exemplary patriotism of Acad. Mihai Drăgănescu is also shown by his relentless work toward the national and international recognition of the personalities of the Romanian culture, such as Ştefan Odobleja. Through a 15 years effort, between 1975 and 1990, during which Acad. Mihai Drăgănescu has delivered numerous talks on the contributions of Ştefan Odobleja, has led the editing of two volumes, Romanian Precursors of Cybernetics [27] and Odobleja between Ampere and Wiener [28], and has edited Odobleja's Consonantist Psychology in Romanian [29], he has succeeded in determining the election of Ştefan Odobleja, posthumously, as member of the Romanian Academy, and has increased the prestige of the Romanian science [19, p.153].

Through his example, Acad. Mihai Drăgănescu has also shown us how to recognize and treasure our professors and mentors. In 1982 he delivers the talk Tudor Tănăsescu - Founder of the Romanian School of Electronics. In 1992 he organizes the conference Tudor Tănăsescu and the Romanian School of Electronics at the Romanian Academy, and leads the editing of the volume Tudor Tănăsescu - Founder of the Romanian School of Electronics [30], solidifying his place in the history of the Romanian science and technology.

These are only a few examples from Acad. Mihai Drăgănescu's life-long sustained effort of promoting past and present values of the Romanian culture, not only through his own publications and speeches, but also through the organization of conferences and through his support for the publication of books in numerous domains.

\section{Mentor and Life Model}

Acad. Mihai Drăgănescu was always a visionary. He was ahead of his time when he introduced the idea of an Information Revolution [8], and when he created the Orthophysics Philosophy [15], and when 
he defined the concept of Functional Electronics [4], and when he defined the concept of Knowledge Society [11], and when he introduced the concept of Consciousness Society [14].

It is well-known that the younger generation is much better adapted to the new social context created by the computers and the Internet than the older ones. In spite of his age, Acad. Mihai Drăgănescu is part of this younger generation. In his seventies, he is the first to publish the first Romanian book on the Internet [20], as well as the first electronic book [31]. He is the one who, in 2001, organizes the first symposium in Romania on the electronic books, as well as the first symposium on the electronic commerce. How could one explain this extraordinary power of assimilation and adaptation that allowed Acad. Mihai Drăgănescu to navigate with such apparent ease the highly dynamic and complex domains of Electronics, Informatics and Philosophy?

In his reception speech at the Romanian Academy, titled "The Philosophical Tension and the Cosmic Feeling”, Acad. Mihai Drăgănescu stated: "If the existence forms material world rings, or universes, then we have to accept that our universe has a sense, a tendency, and the good, in its philosophical sense, corresponds to conforming to this tendency by the human and society, which does not mean strict determinism but, to the contrary, advanced knowledge and high creation power. It can be demonstrated that the philosophic good is not only compatible with the social good but also theoretically derives it, as can also be shown based on humanistic considerations" [32, p.27]. The cosmic feeling, advanced by Acad. Mihai Drăgănescu as solution to the philosophical tension for the understanding of the existence, "calls man to a heroic attitude through thought and action in the direction of the fundamental tendency in the Universe, that is, toward creation and a spiritual attitude which is also a source for strengthening his will, rationality, and lucidity" [32, p.30]. We see here a philosophical justification of the man's action in the direction of good, which Acad. Mihai Drăgănescu exemplifies in the most remarkable manner. We think that precisely his deep understanding of the philosophical tension and the cosmic feeling explains his model patriotic vocation for the progress of the Romanian society, as well as his capacity of overcoming so many obstacles and injustices.

In a long and illustrious career, Acad. Mihai Drăgănescu has lightened and influenced the life of many generations who, as myself, have had the chance of being closer to him, well-thought by him, guided by him, and blessed by him, with unparallel generosity. Acad. Mihai Drăgănescu is a spiritual father and life model for me, the one who has influenced the direction of my life much more than anyone else.

\section{Final Remarks}

The observer of the activity of Acad. Mihai Drăgănescu is amazed by how a person can excel in domains that are so diverse and difficult. It is the genius of Acad. Mihai Drăgănescu who succeeded to discover and define a line of continuity and complementarity that has led him to the development of a unified encyclopedic work integrating the most dynamic domains of the modern society: Electronics, Informatics, and the Philosophy of Science and Society. In his words, "The multidisciplinary approach to problems has become common practice. However, this will not be sufficient if we will not find the integrative factors to melt the multidisciplinarity into a unity, be it the case of understanding a complex reality, or that of achieving goals serving the people and society" [33, p.428]. Discovering these integrative factors is one of the greatest contributions of Acad. Mihai Drăgănescu. One example: "Information technology is a technology of progress in our age, through its two important components: Electronics and Informatics. There is no boundary between them. The physical seed of the contemporary information society is Electronics, or Microelectronics to be precise, and the informational seed is provided by the Informatics" [4, p.15].

The "physical seed" and the "informational seed" may have inspired Acad. Mihai Drăgănescu in his development of the philosophical conception of deep matter: "Under the quantum world there is ... the deep matter governed by two principles: informatter, a matter with informational properties of 
phenomenological type (like the mental senses), and energymatter, a matter with energetic properties, which is unstructured but can be structured by the informatter" [33, p.10].

On the other hand, "Technology is inherently linked to philosophy because, as instrument of becoming, it has an existential role. However, becoming implies coalescing the social factors with the scientific, technological and economic ones, and with the spiritual-cultural life. None of these factors can be estranged from the others without affecting the reality and endangering the socio-human civilization" $[18$, p.127].

What ultimately provides this amazing unity in diversity to the work of Acad. Mihai Drăgănescu is his general view of information which encompasses [33, p.428]:

"I. Philosophy of Information;

II. Science of Information;

III. Technology of Information;

IV. Industry of Information;

V. Economy of Information;

VI. Culture-Information Relationship;

VII. Information Society (including the problems of social intelligence and information democracy);

VIII. Creation (Generation) of Information.”

For Acad. Mihai Drăgănescu, the information "has a multitude of manifestations, it may become thought, consciousness, spirit, computation, poetry, idea, sense. Each of these manifestations may be a support for the understanding of matter and life" [18, p.13].

The encyclopedic work of Acad. Mihai Drăgănescu, spanning Electronics, Philosophy, Informatics, and Society (see http://www.racai.ro/ dragam/), is an impressive and inspiring example of a life dedicated to the Science, Philosophy, and Romanian Society.

\section{Bibliography}

[1] M. Drăgănescu, Electronic Processes in Semiconductor Devices of Circuits (in Romanian), Romanian Academy Press, Bucharest, 1962.

[2] M. Drăgănescu, On Some Microelectronics Problems (in Romanian), Automatica şi electronica, 7 , 1, 31-40, 1963.

[3] M. Drăgănescu, Solid State Electronics (in Romanian), Editura Tehnică, Bucharest, 1972.

[4] M. Drăgănescu, Gheorghe Ştefan, Corneliu Burileanu, Functional Electronics (in Romanian), Vol. I, Editura Tehnică, Bucharest, 1992.

[5] M. Drăgănescu, Microelectronics and Functional Electronics (in Romanian), in: Dan Dascalu and Gh. Brezeanu (Eds.), New Research in Microelectronics, Romanian Academy Press, 9-20, 1994.

[6] M. Drăgănescu, From solid state to quantum and molecular electronics, the deepening of information processing, Invited paper at the International Semiconductor Conference, Sinaia, October 8-11, 1997, published in the volume I of the Conference, p.5-21. http://www.racai.ro/MD75/ 
[7] M. Drăgănescu, Neural Engineering and Neuroelectronics Facing Artificial Consciousness, Communication at the INGIMED II Conference, Bucharest, Dec. 13, 2001; * E-Preprint, MSReader Format, Romanian Federation of Bioengineering.

[8] M. Drăgănescu, System and Civilization, Essays (in Romanian), Editura Politică, Bucharest, 1976.

[9] M. Drăgănescu, The Second Industrial Revolution. Microelectronics, Automatics Informatics: Determining Factors (in Romanian), Editura Tehnică, Bucharest, 1980.

[10] M. Drăgănescu, Informatics and Society (in Romanian), Editura Politică, Bucharest, 1987.

[11] M. Drăgănescu, The Information and Knowledge Society. The Vectors of the Knowledge Society, Study for the Romanian Academy Project "Information Society - Knowledge Society", Bucharest, 9 July 2001, http://www.racai.ro/INFOSOC-Project/

[12] M. Drăgănescu Broadband and the Knowledge Society, Communication presented at the International Conference Information Society Technologies for Broadband Europe, 9-11 October 2002, Marriott Grand Hotel, Bucharest, România. http://www.racai.ro/ dragam/BROADBANDINTERNET-AND-THE-KNOWLEGDE.pdf

[13] C. Noica, A Work for the Century (in Romanian), Contemporanul, 20 June 1986.

[14] M. Drăgănescu, The Consciousness Society (in Romanian), Romanian Academy Institute for Artificial Intelligence, Bucharest, 2007, ISBN 978-973-0-05307-4

[15] M. Drăgănescu, The Depth of Existence, Editura Politică, Bucharest, 1979, http://www.racai.ro/books/doe/

[16] M. Drăgănescu, Orthophysiscs (in Romanian), Editura Ştiinţifică şi Enciclopedică, Bucharest, 1985. http://www.racai.ro/ dragam/ortof.html

[17] M. Drăgănescu, Spirituality, Information, Matter. Essays (in Romanian), Romanian Academy Press, Bucharest, 1988.

[18] M. Drăgănescu, Information of Matter (in Romanian), Romanian Academy Press, Bucharest, 1990.

[19] M. Drăgănescu, Essays (in Romanian), Romanian Academy Press, Bucharest, 1993.

[20] M. Drăgănescu, L'Universalité Ontologique de L'information. Préface et notes par Yves Kodratoff, Romanian Academy Press, Bucharest, 1996. HTML edition by Dorin Marcu, http://www.racai.ro/books/draganescu/

[21] M. Drăgănescu, Principes d'une science structurale-phénoménologique, Bulletin de la Classe des Lettres et des Sciences Morales et Politiques, Academie Royale de Belgique, 6e série, Tome IV, 7-12, 255-311, 1993.

[22] M. Kafatos, R. Nadeau, The Conscious Universe, Springer Verlag, New York, 1990.

[23] M. Drăgănescu, The Fundamental Consciousness of Existence (in Romanian), Academica, JanuaryMarch 1998. http://www.racai.ro/MD75/

[24] M. Drăgănescu, M. Kafatos, Generalized Foundational Principles in the Philosophy of Science, paper presented at the Conference on "Consciousness in Science and Philosophy" Charleston, Illinois, 6-7 Nov 1998, published in The Noetic Journal, Vol.2, No.4, Oct. 1999, 341-350, republished in the vol. Science and the Primacy of Consciousness, Intimation of a 21st Century Revolution, Richard L. Amoroso and others (eds), Orinda: The Noetic Press, 2000, Chapter 9, 86-98. Also * e-copy in MSReader format. 
[25] M. Kafatos, M. Drăgănescu, Toward an Integrative Science, NOESIS, XXVI, 2001. http://www.racai.ro/MD75/

[26] M. Drăgănescu, Caryatids of Thought (in Romanian), Romanian Academy Press, Bucharest, 1996.

[27] M. Drăgănescu, Constantin Bălăceanu, Victor Săhleanu, Gheorghe Petrovici, Gheorghe Ştefan and Alexandru Giuculescu, Romanian Precursors of Cybernetics (in Romanian), Romanian Academy Press, 1979.

[28] M. Drăgănescu, P. Golu, C. Bălăceanu and A. Giuculescu, Odobleja between Ampere and Wiener, Romanian Academy Press, 1981.

[29] Şt. Odobleja, Consonantist Psychology (in Romanian), with an introductory study by Mihai Drăgănescu and Pantelimon Golu, Editura Ştiinţifică şi Enciclopedică, Bucharest, 1982.

[30] M. Drăgănescu, A. Rusu, Şt. Iancu (eds), Tudor Tănăsescu, the Founder of the Romanian School of Electronics (in Romanian), Editura Dorotea, Bucharest, 2001.

[31] M. Drăgănescu, Tudor Tănăsescu and the Romanian School of Electronics (in Romanian), Bucharest, 7 March 2001, * e book, MSReader format, edition dragam@ racai.ro

[32] M. Drăgănescu, The Philosophical Tension and the Cosmic Feeling. Romanian Academy Reception Speech, 6 September 1990. Answer by Acad. Zoe Dumitrescu Buşulenga. Opening Remarks by Acad. Nicolae Cajal, Romanian Academy Press, Bucharest, 1991.

[33] M. Drăgănescu, The Ring of the Material World, Editura Ştiinţifică şi Enciclopedică, Bucharest, 1989.

Gheorghe Tecuci is Member of the Romanian Academy, Professor of Computer Science and Director of the Learning Agents Center in the Volgenau School of Information Technology and Engineering at George Mason University, and Visiting Professor and former Chair of Artificial Intelligence at the US Army War College. 